\title{
An Enormous Compensatory Hyperinflated Lung After Pneumonectomy: Pseudo-horseshoe Lung
}

Çisel Yazgan 1 , [MD]

ORCID: 0000-0003-2804-7321

Damla Eyupoglu², [MD]

ORCID: 0000-0002-1617-5134

Sevinc Sarinc Ulasli ${ }^{3},[M D]$

ORCID: 0000-0003-3144-7932

Deniz Koksal' ${ }^{3}$, [MD]

ORCID: 0000-0001-8374-3691

'Hacettepe University School of Medicine, Department of Radiology, Ankara, Turkey.

${ }^{2}$ Hacettepe University School of Medicine, Department of Internal Medicine, Ankara, Turkey.

${ }^{3}$ Hacettepe University School of Medicine, Department of Chest Diseases, Ankara, Turkey.

Corresponding Author: Sevinc Sarinc Ulasli Hacettepe University School of Medicine, Department of Chest Diseases, Ankara, Turkey.

E-mail: sevincsarinc@gmail.com

\section{w ABSTRACT Con}

Pneumonectomy causes a number of anatomical changes within the thoracic cavity to improve the diffusion capacity of the remaining lung. A 41-year-old female was admitted with the complaints of cough and purulent sputum for the last two weeks. Her past medical history revealed that she underwent left pneumonectomy for bronchiectasis at the age of 10 due to massive hemoptysis. Massive compensatory hyperinflation of the right lung, which was herniated anteriorly across the midline, and extreme mediastinal shift were observed in computed tomography which is called pseudo-horseshoe lung. Although postpneumonectomy lung compensation can diminish by advanced age, clinicians should be aware that it can be observed in adult patients who had pneumonectomy at early ages.

Keywords: Pneumonectomy, pseudo-horseshoe lung

Received: 29 April 2020, Accepted: 18 September 2020,

Published online: 31 December 2020

\section{INRODUCTION}

Pneumonectomy causes a number of anatomical changes within the thoracic cavity that improve the diffusion capacity of the remaining lung [1]. In experimental animal models, pneumonectomy initiates compensatory, regenerative growth of the remaining lung tissue that restores normal mass, structure and function [2]. The main determining factors of compensatory lung growth after pneumonectomy are stretch, pulmonary bloodflow, hypoxia, age, sex and growth factors [3]. Although post-pneumonectomy lung compensation can diminish by advanced age, clinicians should be aware that it can be observed in adult patients who had pneumonectomy at early ages. In this case report, we presented the images of a patient who had a left pneumonectomy due to bronchiectasis at the age of 10 .

\section{CASE PRESENTATION}

A41-year-oldfemalewasadmitted toourdepartment with cough and purulent sputum for the last two weeks. Her past medical history revealed that she underwent left pneumonectomy for bronchiectasis at the age of 10 due to massive hemoptysis. On physical examination, chest auscultation was normal apart from the absence of lung sounds on the basis of left hemithorax. The apical heart beat was extremely shifted to left. Chest X-ray showed 
the hyperinflated right lung and mediastinal shift to the contralateral hemithorax (Figure 1). There was also radiolucency on the left hemithorax in spite of the patient's pneumonectomy history. A computed tomography (CT) scan demonstrated massive compensatory hyperinflation of the right lung, which was herniated anteriorly across the midline, and extreme mediastinal shift. Additionally, distal part of the trachea and right main bronchus were abnormally narrowed (Figure 2a\&2b).

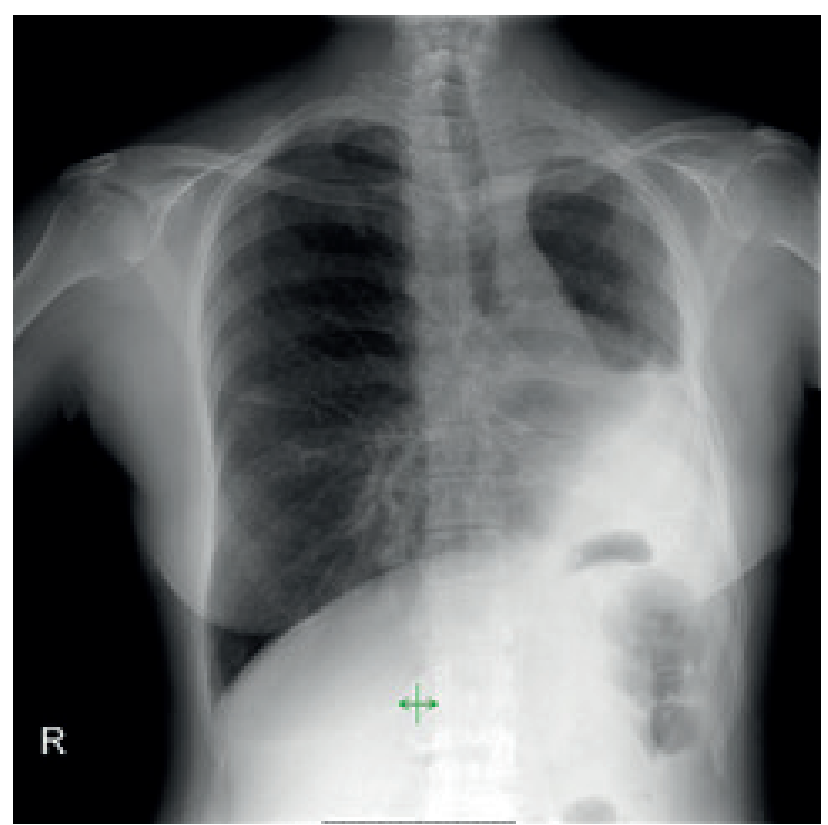

Figure 1. Chest X-ray shows overexpansion of the right lung and radiolucency in left pneumonectomy space

\section{DISCUSSION}

In the literature this appearance is defined as pseudo-horseshoe lung $[4,5]$. The rotational shifting of mediastinal great vessels and compression of main bronchus are delayed complications of pneumonectomy which usually occurs after right pneumonectomy [6,7]. Patients mainly complain about dyspnea and recurrent pulmonary infections. The presented patient underwent a left pneumonectomy and right main bronchus system was compressed. The patient did not complain about recurrent pulmonary infections.

In conclusion; pneumonectomy at the early ages can cause an enormous compensatory hyperinflation of the remnant lung. Chest X-ray may be insufficient and misleading to identify the exact anatomic changes due to pneumonectomy. $\mathrm{CT}$ is the best modality in demonstrating postpneumonectomy changes including the narrowing and compression of trachea and main bronchi.

\section{CONFLICT Of INTEREST STATEMENT}

All authors have no conflict of interest.
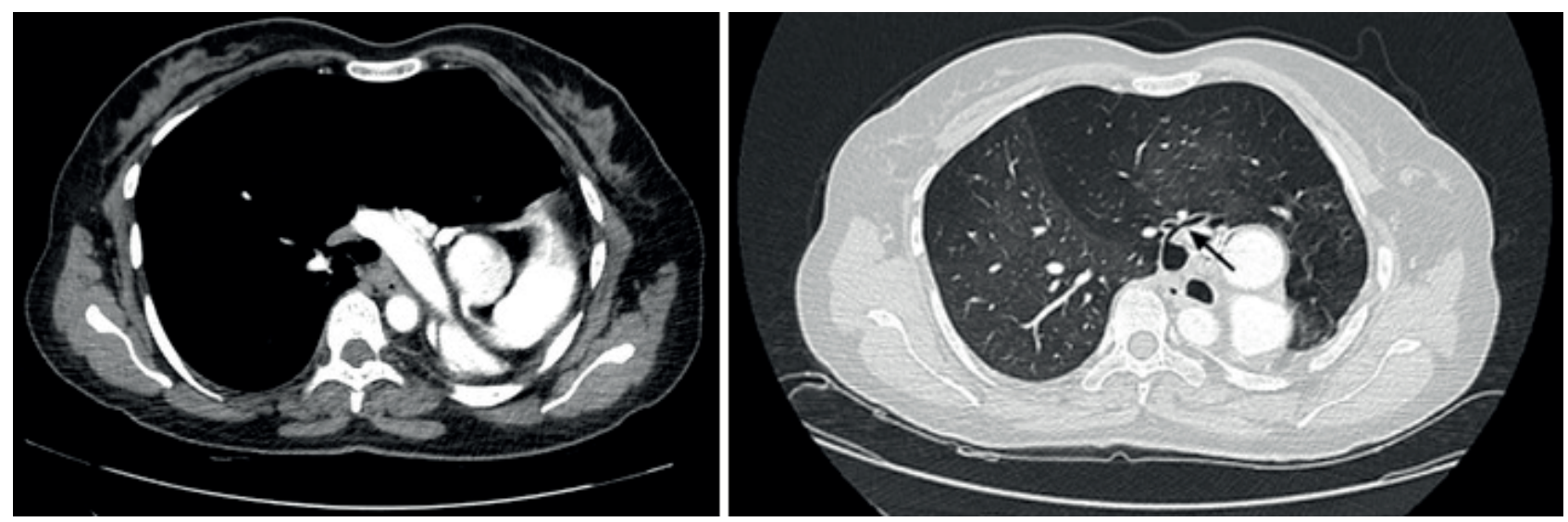

Figure 2a\&2b. Axial CT image demonstrates (a) anterior herniation of the hyperexpanded right lung and (b) narrowed right main bronchus (arrow) 
[1] Brown LM, Rannels SR, Rannels DE. Implications of post-pneumonectomy compensatory lung growth in pulmonary physiology and disease. Respir Res 2001; 2(6): 340-7.

[2] Fernandez LG, Mehta CK, Kron IL, et al. Reinitiation of compensatory lung growth after subsequent lung resection. J Thorac Cardiovasc Surg 2007; 134(5): 1300-5.

[3] Paisley D, Bevan L, Choy KJ, et al. The pneumonectomy model of compensatory lung growth: insights into lung regeneration. Pharmacol Ther 2014; 142(2): 196-205.

[4] Salman Siddiqi M, Kumar Sharma A, Al Sabti H. Pseudohorseshoe lung due to compensatory hyperinflation. Asian Cardiovasc Thorac Ann 2016; 24(7): 731.
[5] Gallimore R, Gregoire-Bottex MM, Bauler L. PseudoHorseshoe Lung Herniation Following Tracheoesophageal Fistula Repair in a Child with Situs Inversus Totalis Am J of Respir Crit Care Med 2020; 201: A4998.

[6] Chae EJ, Seo JB, Kim SY, et al. Radiographic and CT findings of thoracic complications after pneumonectomy. Radiographics 2006; 26: 1449-68.

[7] Alpert JB, Godoy MC, Degroot PM, et al. Imaging the post-thoracotomy patient: anatomic changes and postoperative complications. Radiol Clin North Am 2014; 52: 85-103. 